
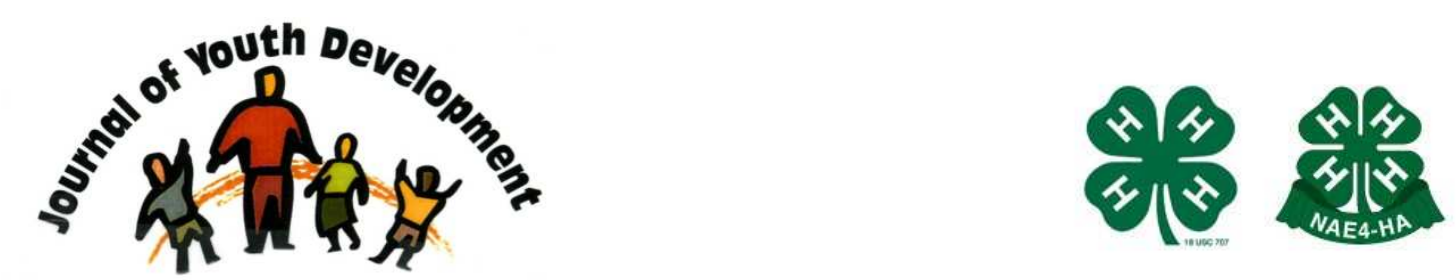

Bridging Research \& Practice

\title{
The Role of Adolescent Development in Social Networking Site Use: Theory and Evidence
}

\author{
Drew P. Cingel \\ Northwestern University \\ Evanston, IL \\ drewc@u.northwestern.edu \\ Ellen Wartella \\ Northwestern University \\ Evanston, IL \\ Marina Krcmar \\ Vrije University Amsterdam \\ The Netherlands \\ krcmarm@wfu.edu
}




\title{
JOURNAL OF YOUTH DEVELOPMENT \\ bridging research and practice

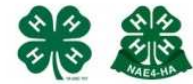

Volume 9, Number 1, Special Edition 2014

Article 140901FA002

\section{The Role of Adolescent Development in Social Networking Site Use: Theory and Evidence}

\author{
Drew P. Cingel and Ellen Wartella \\ Northwestern University \\ Marina Krcmar \\ Vrije University Amsterdam
}

\begin{abstract}
Using survey data collected from 260 children, adolescents, and young adults between the ages of 9 and 26, this paper offers evidence for a relationship between social networking site use and Imaginary Audience, a developmental variable in which adolescents believe others are thinking about them at all times. Specifically, after controlling for a number of variables, results indicate a significant, positive relationship between social networking site use and Imaginary Audience ideation. Additionally, results indicate a positive relationship between Imaginary Audience ideation and Facebook customization practices. Together, these findings provide evidence, based on Vygotskian developmental theory, for a general consideration of the role that currently available tools, in this case social networking sites, can have on development. Thus, findings implicate both the role of development on social networking site use, as well as the role of social networking site use on development. Overall, these findings have important implications for the study of media and human development, which are discussed in detail.
\end{abstract}

\section{Introduction}

There is little question that adolescents' use of social networking sites has grown exponentially over the past few years, both in terms of the percentage of adolescents with online profiles as well as the amount of time they spend on such sites (Lenhart, Purcell, Smith, \& Zickuhr, 2010). Given these high rates of use, a number of research studies have examined the relationships between social networking site use and a number of different outcome measures among adolescents, including impression formation (Antheunis, \& Schouten, 2011), identity 
experimentation (Valkenburg, \& Peter, 2008), and social self-esteem (Valkenburg, Peter, \& Schouten, 2006). While a number of these studies take a developmental perspective, as called for by Wartella, Caplowitz, and Lee (2004), in order to examine children's and adolescents' use of social networking sites, fewer have explicitly examined the interaction of social networking site use on the experience of certain development phases. Therefore, in the present paper, we have two overarching goals. First, we will use existing theory and previous findings to offer support for the study of the interaction between social networking site use and children and adolescent development. Second, we will present findings collected from a sample of 9-26 yearolds to provide evidence for a relationship between social networking site use and a developmental variable during adolescence, the Imaginary Audience (Elkind, 1967). This variable is particularly important to consider given its association with identity development during adolescence. Together, theory and data will illuminate the importance of understanding adolescents' differential uses of social networking sites based on developmental stage, as well as the role that social networking site use has on development.

\section{Imaginary Audience}

First conceptualized by Elkind (1967), Imaginary Audience was seen as a sub-construct of adolescent egocentrism (Piaget, 1952), occurring between the ages of 13 and 15. By this age, adolescents have acquired formal-operational thought, which means that they can think about their thoughts as well as the thoughts of others. They cannot, however, always understand the direction of those thoughts; that is, they often assume that others' thoughts are directed at them, given their own heightened egocentrism (Elkind, 1967). Taken together, since adolescents think about themselves often, and think that others are constantly thinking about them, they develop an Imaginary Audience, or an unseen other that is constantly thinking about and judging them. (Elkind, 1967).

This understanding of Imaginary Audience underwent a reconceptualization in the mid-1980's by Lapsley and colleagues (see Lapsley, 1985; Lapsley, \& Murphy, 1985; Lapsley, \& Rice, 1988; Lapsley, FitzGerald, Rice, \& Jackson, 1989 for a review). Here, Imaginary Audience ideation is seen as a byproduct of separation-individuation concerns, where the adolescent is interested in balancing their own needs and understanding of the self from that of their parents. What is important to note here is that under both conceptualizations, the developmental trajectory of Imaginary Audience ideation generally rose from age 13 before dropping off around age 15 .

Although it is possible to argue that social media use should be related to a more stable trait variable such as self-consciousness, current data suggest that this may not be the case. Findings (see Lenhart, 2009a; Lenhart, 2009b; Lenhart, et al., 2010; Subrahmanyam, Reich, Waechter, \& Espinoza, 2008) suggest that adolescents use social media in very different ways and with very different expectations than older adults. For example, adolescents generally use social networking sites more often than adults just out of college, but also engage in more customization practices while on social networking sites (Lenhart, et al., 2010). That is, they post more pictures, status updates, and comments. Given these findings in regards to age, it appears that one's comfort and experience with technology does not necessarily influence the ways in which they use social media; rather, it may have something to do with the processes of development. Additionally, and while not extensively studied in current literature, some research has found an elongation in Imaginary Audience ideation across adolescence and into young adulthood (e.g. Schwartz, Maynard, \& Uzelac, 2008), a departure from the findings of Elkind (1967) and Lapsley, et al. (1989). Taking these findings together, it is increasingly important to understand how media use might be related to changes in certain developmental trajectories. But how might this be the case? 
Vygotsky and Adolescents' Inner Speech

In his book, Mind in Society, Vygotsky (1978) shed light on the importance of adolescent's "inner speech" as well as the ability of media and technological tools to socialize youth. This theory of development stands in contrast to Piagetian theory (Piaget, 1952), in that Vygotsky argued that development was both historically and culturally situated and the result of a child or adolescent's specific socialization experiences based on how he/she represents those experiences in their inner life-what Vygotsky called their inner speech. Thus, development, to Vygotsky, is not necessarily bound by age, as is generally argued for in Piagetian theory. Inner speech refers to the tools by which youth make sense of their growing cognitive capacities and socialization experiences while gradually internalizing what are at first externally experienced skills. In this sense, both the Imaginary Audience of contemporary developmental theory and the "inner speech" of Vygotsky are important developmental activities by which individuals incorporate into their mental life their growing skills, understandings, and experiences. Moreover, in the Vygotskian sense, the specific external tools available to the developing child and adolescent are important in structuring development. In this sense, contemporary social media, almost universally engaged in by today's adolescents, are dominant tools of child and adolescent development, certainly in our culture and at this time. Considering previous findings of an elongation of the developmental trajectory of Imaginary Audience ideation (e.g. Schwartz, et al., 2008), and the potential role of media in adolescent development, we ask:

RQ1: How do levels of Imaginary Audience ideation differ between the ages of 9 and 26?

\section{The Role of Adolescent Development on Social Networking Site Use}

Given this socio-historical framework for the study of media use and development, it makes sense to examine the role of social networking sites, a currently integral form of media in the lives of adolescents, on developmental trajectories. Therefore, we will first consider the importance of social networking sites in the lives of adolescents and provide a theoretical argument for the relationship between development and use of such sites.

While we have written generally about social networking sites to this point, it is important to specifically consider the affordances of Facebook, as this site currently has more than one billion individual users (Cohen, 2012). On Facebook, users can connect with others through a variety of means, from posting information about the self to sending messages to others. This is potentially of great importance to adolescents, as the creation and maintenance of friendships is given high priority (Nickerson, \& Nagle, 2005; Sullivan, 1953; Vartanian, 1997). Additionally, Facebook can be used as a mechanism by which adolescents can maintain ties with their parents (see Kanter, Afifi, \& Robbins, 2012), while experimenting with their identity online, thereby working to individuate themselves (Valkenburg, \& Peter, 2008). Thus, it seems likely that Facebook is a tool that adolescents can use beneficially while engaging in the separationindividuation tasks inherent in Imaginary Audience ideation (see Lapsley, et al., 1989).

In addition, past research has begun to look at the role that social networking site use has on impression formation, finding generally that having attractive friends or attractive, positive wall posts is related to more positive ratings of the adolescent (Antheunis, \& Schouten, 2011). Similarly, Walther, Van Der Heide, Kim, Westerman, and Tong (2008) found, among collegeaged participants, that positive statements on an individual's Facebook wall were related to increases in ratings of attractiveness for that individual. Relatedly, Burke, Marlow, and Lento (2009) found that social networking site users will post more information on their profiles if they perceive that their friends post a lot of information on their profiles. Taking these findings 
together, it is clear that the information one puts out about oneself on Facebook has important implications for how one is seen by others, as well as how others behave on the site. This is an especially important consideration for an individual high in Imaginary Audience ideation. McLaughlin and Vitak (2012) found that users interpret the profiles of highly-regarded others, and use these interpretations to guide the information they use to customize their profiles. Given the customization options available on Facebook, it is relatively easy for users of all ages to control the information they post about themselves, and therefore to a degree, the way they will be seen by others.

Overall then, previous research would seem to indicate that all users of Facebook, including adolescents, are able to perceive the social norms that operate in the Facebook community and then use that information to create a profile that accentuates positive aspects of the self (see McLaughlin, \& Vitak, 2012). It makes sense then, that for individuals high in Imaginary Audience ideation, Facebook customization rates will also be higher, as users react to their perceived Imaginary Audience on the site by examining the norms operating in that space. Thus,

$\mathrm{H} 1$ : Controlling for age, overall Facebook use, and self-consciousness, Imaginary Audience ideation will be positively related to Facebook customization.

\section{The Role of Social Networking Site Use on Adolescent Development}

To this point, we have used theory and previous findings to argue for the importance of considering developmental variables when studying social networking site use. Additionally, we have argued for a consideration of the role that development can have on differential uses of social networking media, especially in terms of customization practices. Finally, we will consider the reciprocal relationship to this previous argument: the role that social networking site use might have on development. As discussed earlier, in a Vygotskian sense, the tools available to the adolescent at a particular moment in time are crucial to their ways of making sense of the world, and thus, their general development. Therefore, while it is possible for development stage to drive adolescents' use of given tools, in this case social media, it is also possible and indeed likely that these tools are also related to adolescents' general development.

While not previously used in this context, the theoretical mechanism of behavioral rehearsal can be used to understand how Facebook use can be related to Imaginary Audience. Behavioral Rehearsal refers to a three part process that people go through when considering a particular behavior change, from comparing oneself to others, and thinking about how to engage in the desired change, before actually engaging in the changed behavior (Remondet, Hansson, Rule, \& Winfrey, 1987). As discussed above, research indicates that social networking site users can and do understand the social norms that operate in their online community. This, however, is merely the first step of behavioral rehearsal. Previous research indicates that adolescents engage in the cognition and offline-action stages of this behavioral model online as well. For example, using qualitative interviews of adolescent Facebook users between the ages of 11 to 18, Moreno, Briner, Williams, Walker, and Christakis (2009) found that information posted on social networking sites about displays of alcohol use or attitudes about alcohol are interpreted as real thoughts and behaviors by others in this age group. Additionally, it has been argued that Facebook, as a form of media, may be particularly influential among adolescents due to its combination of interpersonal communication and mass media (Fogg, 2008). In fact, qualitative research complied by Moreno, et al. (2010) suggests that adolescents perceive alcohol-related pictures as an effort to appear "cool." Thus, research seems to indicate that adolescent Facebook users think posted information is real, and may be persuaded by this information. 
Therefore, it is possible that these representations may cause users to alter their beliefs, such that their beliefs come to match the beliefs that are seen as normative on social networking sites. This is a similar argument to that of Moreno and colleagues (2009). As these authors note, social networking sites provide a venue for the exploration of identity, with opportunities for maintenance, adaptation, and others' feedback (Moreno, 2010). These findings illustrate how social networking sites can be used to shape identity; after comparing their social networking page to others, adolescents have the opportunity to tailor their profiles in such a way to accentuate or perhaps even manufacture the "cool" behaviors in which they engage, thereby changing a small facet of their identity. In total, adolescents' sense of who they are and who they want to be plays an important role in the ways in which they select and engage with social networking sites (see Steele, \& Brown, 1995). Overall, the affordances of Facebook allow for profiles to be customized quickly and easily, in an attempt to show off this constructed identity that is based on a comparison, cognition, and finally, actual behavioral change. The ability for Facebook users to quickly and easily assess the normative values of this online forum coupled with the customization option available to them makes it easy to compare one's self to others and change one's online identity when necessary. In doing so, users are acting toward a perceived online audience. This continual thinking about the self and how it relates to this other should then manifest itself in heightened Imaginary Audience ideation. Thus,

H2: Controlling for age, Facebook customization, and self-consciousness, overall Facebook use will be positively related to Imaginary Audience ideation.

Using Vygotskian developmental theory, we have argued for a consideration of the reciprocal relationships between media and human development. As exhibited in this review of literature, users of Facebook can, and do, act toward and react to a perceived, online Imaginary Audience. That is, they can post information about the self, see the responses they get from others, use these responses to inform later customization practices, before actually engaging in those customization practices. Thus, we argue that Facebook use can be cyclical in nature, in that developmental stage should be related to how users engage with the site through customization, and subsequent use of the site should be related development. Next, we seek to provide additional evidence for these arguments using data that are detailed below.

\section{Method}

Participants. 260 participants between the ages of 9 and 26 completed the survey instrument. Thus, participants ranged from fourth graders to young, working adults. Overall, females represented $57.7 \%(n=150)$ of the final sample. $86.2 \%(n=224)$ of the sample indicated their race as white, $7.7 \%(n=20)$ indicated their race as African-American, $2.7 \%(n=7)$ indicated their race as Hispanic/Latino, and 3.5\% $(n=9)$ indicated their race as Asian.

Procedure. For student recruitment, the principal at the participating elementary and middle school was approached prior to data collection and asked to provide consent. One week prior to the researcher being in the school, a parental recruitment letter and consent form was sent home with each student in these grades. Teachers collected completed consent forms as they were returned, keeping track of which students had brought one back. On the day of data collection, participating students completed the survey in an unused classroom. After assenting and completing the survey, each participant handed in their survey and was thanked for their time. 
Additionally, parents whose children were in the appropriate age range (10-17) were identified via a convenient snowball sample and given either a packet containing a recruitment letter, a parental consent form, a child assent form, and the survey instrument, or an online version of these documents was sent to their email address. Those whose children completed a paper and pencil version of the survey were given instructions for returning the survey and necessary consent materials to a member of the research team. Children and adolescents recruited via this method received a $\$ 5$ gift card in exchange for their participation.

College-aged students, recruited from participating classrooms, were offered a nominal amount of extra credit upon completion of the survey materials. An email explaining the purpose of the research, along with a link to the online survey, was sent to the roster of participating classes. Participants could click on the embedded link and complete the online survey, which took approximately 20 minutes, at a time and place of their choosing. This same online survey was used for participants past college-age, who were identified via a convenient snowball sample.

\section{Measures}

Self-consciousness. An adaptation of the 23-item Fenigstein Self-Consciousness scale was used to measure private and public self-consciousness, different constructs from that of Imaginary Audience (Fenigstein, Scheier, \& Buss, 1975). In an effort to keep the overall instrument concise and thereby usable with younger audiences, this measure was shortened to 8 items using data compiled during a pilot test of this instrument. This scale was reliable, with a Cronbach's alpha of .83.

Facebook Use. Participants were asked to self-report on a number of questions aimed at understanding the extent to which each uses Facebook. Participants were asked to report the amount of time they spent on Facebook each day as well as the number of friends that they have on their Facebook profile. They were also asked to report how many times per day they log into Facebook as well as the length of time that they have had a Facebook profile.

Facebook Customization. A Facebook customization scale was used in order to understand the extent to which and how often each age group modifies their Facebook profile page. The scale individuated a number of Facebook customization techniques, such as the number of times users change their profile picture, change their status, add photos, and comment on others' walls. For example, participants were asked how often they engage in these aforementioned behaviors on a 1 to 4 Likert-type scale anchored by never and often. This scale was reliable, with a Cronbach's alpha of .93.

Imaginary Audience. The New Imaginary Audience Scale (NIAS) was used to determine the extent to which participants have a tendency to engage in Imaginary Audience ideation (Lapsley et al., 1989). This scale consists of 42 items measured on a Likert-type scale where an answer of 1 indicates that the participant never engages in the behavior and an answer of 4 indicates the participant engages in the behavior often. Participants are asked to respond to how often they think about certain notions or ideas. Sample questions include "being rejected by a girlfriend or boyfriend," "imagining what everyone will think if you became famous," and "imagining how others would feel if you were gone (Lapsley, et al., 1989)." This measure was reliable, with a Cronbach's alpha of .95. 


\section{Results}

First, RQ1, which asked about the relationship between age and Imaginary Audience ideation, was tested by using a univariate ANOVA. Age was split into five developmentally-meaningful groups: 9-12, 13-15, 16-18, 19-22, and 23-26 (Erikson, 1974). This ANOVA indicated that there was a significant difference between the age groups on their Imaginary Audience scores $(F(4$, $244)=5.32, p<.01)$. A post-hoc Bonferroni correction indicated that $9-12$ year olds scored significantly lower on Imaginary Audience than 13-15 year olds and 19-22 year olds. Thirteen to fifteen year-olds and 19-22 year-olds differed significantly from 23-26 year-olds, while there were no differences between the 16-18 year-old age group and all other age groups on scores of Imaginary Audience (please see Table 1). Thus, Imaginary Audience ideation increases significantly from age 9 to 13 and then remains relatively stable before dropping around age 23 .

Table 1

Difference between age groups on imaginary audience ideation

\begin{tabular}{|l|l|l|}
\hline & Mean & Std. Deviation \\
\hline $9-12$ year-olds & $2.10^{\mathrm{a}}$ & 0.60 \\
\hline $13-15$ year-olds & $2.46^{\mathrm{b}}$ & 0.62 \\
\hline $16-18$ year-olds & $2.37^{\mathrm{ab}}$ & 0.40 \\
\hline $19-22$ year-olds & $2.42^{\mathrm{b}}$ & 0.50 \\
$23-26$ year-olds & $2.04^{\mathrm{a}}$ & 0.58 \\
\hline
\end{tabular}

Note: Means that do not share a common subscript differ significantly at $p<.05$.

To test $\mathrm{H} 1$, which asked about the relationship between Imaginary Audience ideation and Facebook customization while controlling for age, overall Facebook use, and self-consciousness, a hierarchical multiple regression was used. First, the three control variables were entered on step one and were significant $\left(R=.64, R^{2}=.41, F(3,209)=49.11, p<.01\right)$. Specifically, age $(\beta=.35, p<.01)$, overall Facebook use $(\beta=.36, p<.01)$, and self-consciousness $(\beta=.15, p$ $<.05)$ were all significantly related to increases in Facebook customization practices. Next, Imaginary Audience score was entered into the model on step two. This block was significant as well $(R=.65, F(4,208)=38.29, p<.01)$, with a significant change in $R^{2}\left(R^{2} \Delta=.01, F \Delta(1\right.$, $208)=3.82, p<.05)$. Specifically, Imaginary Audience ideation was significantly related to increase Facebook customization $(\beta=.13, p<.05)$, whereas self-consciousness was no longer significant $(\beta=.09, p=$ n.s. $)$. Overall, $\mathrm{H} 1$ was supported, as Imaginary Audience ideation proved to be a better predictor of Facebook customization practices than one's level of selfconsciousness.

A hierarchical multiple regression was used to test $\mathrm{H} 2$, which predicted that, after controlling for age, Facebook customization, and self-consciousness, overall Facebook usage would be positively related to Imaginary Audience scores. Results supported this hypothesis. First, age, Facebook customization, and self-consciousness were entered on step one $\left(R=.57, R^{2}=.32, F\right.$ $(3,210)=32.69, p<.01)$. Specifically, Facebook customization $(\beta=.21, p<.01)$ and selfconsciousness $(\beta=.48, p<.01)$ were individually significant. Next, one's overall time spent on Facebook was entered on step two. This was significant $(R=.58, F(4,209)=33.23, p<.01)$ 
and the change in $R^{2}$ from step one to step two was significant as well $\left(R^{2} \Delta=.02, F \Delta(1,208)\right.$ $=4.95, p=<.01$ ). Individually, overall Facebook time was significantly related to Imaginary Audience score $(\beta=.15, p<.05)$, while Facebook customization was no longer significant $(\beta=$ $.14, p=$ n.s.) thereby supporting the relationship proposed in $\mathrm{H} 2$.

\section{Discussion}

Summary of Findings. Similar to the findings of Schwartz, et al. (2008), the data presented here indicate a general elongation of the developmental trajectory of Imaginary Audience ideation well past how it has been seen historically (Elkind, 1967; Lapsley, et al., 1989). Specifically, there was no significant difference in Imaginary Audience score from age 13 to 22; it is important to note that this occurred using the same measure of Imaginary Audience as Lapsley, et al. (1989) and Vartanian (1997). Second, results indicate that there is a significant, positive relationship between Facebook use and Imaginary Audience ideation after controlling for age, Facebook customization, and self-consciousness. Finally, results indicated a significant positive relationship between Imaginary Audience ideation and Facebook customization, after controlling for overall Facebook use, and self-consciousness. After entering Imaginary Audience on the second step of the regression model, self-consciousness was no longer a significant predictor of Facebook customization, indicating a developmental variable is a better predictor of this relationship than a trait variable.

Practical and Theoretical Implications. Taken together while considering theory and previous findings, these preliminary results are illustrative of the role that media use can have on development, as well as the differential role that developmental stage can have on certain forms of media use. Overall, the findings of this study generally contrast the robust series of findings in the extant literature on the Imaginary Audience. For example, using the NIAS as a measure, Vartanian (1997) replicated the findings of Lapsley, et al. (1989). The NIAS is the same measure that was used in the present study; here, however, findings did not follow similar patterns. More so, however, Imaginary Audience scores were especially heightened for those high in Facebook use. Therefore, one possible explanation for the changes in the developmental trajectories of Imaginary Audience ideation may be heavy Facebook usage among children and adolescents. A host of other factors, including other tools and technologies currently available, not measured by this study are almost certainly at play, which together result in changes in the trajectories of these developmental variables. The results of this study, however, do shed light on one such variable by relating it to Imaginary Audience.

This is an important finding for a number of reasons. With the sheer number of children and adolescents on Facebook, as well as the vast amount of time that many of them spend using it, it is important to consider the role that Facebook might play in not only daily life, but developmentally as well. This may have serious implications for the future, as more and more children around the world begin to use social media in even higher quantities and at earlier ages. Therefore, it may be important to consider other forms of social media because the affordances of these technologies are similar to those of Facebook. Similar to Facebook, most other social media allow users to create some type of profile, control the information that they present to the world, and monitor the identity that they present on their account. As evidenced here, these affordances may change the way we think about ourselves and others.

Additionally, results indicate that heightened Imaginary Audience ideation is related to differentiate use patterns among Facebook users, such that those high in this developmental variable are also higher in rates of Facebook customization. This is an important finding to 
consider when studying general social networking site use. While various ages are generally lumped together in order to present descriptive statistics (e.g. Lenhart, et al., 2010), these data indicate that researchers must consider the developmental stage of the user. Furthermore, researchers must begin to think about the cyclical relationship from individuals' social networking site use, to developmental variables and trajectories, and back to specific practices on the site. In sum, the findings presented in this paper provide contemporary evidence to Vygotsky's (1978) assertion that the tools and technologies available to children and adolescents at a given place and time are important to consider when examining how they structure their inner speech and their development in general.

Limitations and Conclusion. The main limitations of the study arise from its sample. Although efforts were made to diversify the sample, especially in terms of geography, educational background and race, the majority of the sample was white. Among the sample older than 18, most participants were either college educated or currently in college. This could have implications for our findings, given that Facebook use is nearly ubiquitous across race and socioeconomic status in the United States. Additionally, we attempted to make longitudinal claims in regards to our data and findings although the survey design was cross-sectional. In examining the demographical data across all ages, we have no reason to believe that any age group differs significantly from one another on gender, race, and socioeconomic status; however, without truly longitudinal data or the ability to follow particular individuals over the course of a few years, it is impossible to tell if the age groups in our sample are truly equal in terms of their Facebook use and Imaginary Audience ideation. Longitudinal data would give researchers the ability to make truly causal claims in regard to the relationship between Facebook and Imaginary Audience and is an important direction for future research in addition to a consideration of different media use variables.

Taken together, however, the theory, previous findings, and current research presented in this paper argue toward a consideration of the role that developmental variables play on adolescents' experiences on social networking sites. Considering the role of developmental variables such as Imaginary Audience ideation will provide researchers with a more nuanced and thus, more complete view of the relationship between the use of such sites and development. It is also important to consider the role that media use has on development. These views will be vitally important, as researchers continue to examine the relationships between development, children and adolescents' engagement with social networking sites, and their media use in general.

\section{References}

Antheunis, M.L., \& Schouten, A.P. (2011). The effects of other-generated and system generated cues on adolescents' perceived attractiveness on social networking sites. Journal of ComputerMediated Communication, 16(3), 391-406. doi: 10.1111/j.10836101.2011.01545.x

Burke M., Marlow, C., \& Lento, T. (2009). Feed me: Motivating newcomer contribution insocial network sites. In: Proceedings of the 27th Annual SIGCHI Conference on Human Factors in Computing Systems. New York: ACM, 945-954.

Cohen, N. (2012). The breakfast meetings: Grilling for James Murdoch, and Facebook tops 900 million users. The New York Times. Retrieved September 13, 2012 from:http://mediadecoder.blogs.nytimes.com/2012/04/24/the-breakfast-meeting-grilling-for james-murdoch-and-facebook-tops-900-million-users/ 
Elkind, D. (1967). Egocentrism in adolescence. Child Development, 38(4), 1025-1034.

Erikson, E.H. (1974). Youth: Fidelity and diversity. In A.E. Winder and D.L. Angus (Eds.), Adolescence: Contemporary studies. New York: American Book Company.

Fenigstein, A., Scheier, M.F., \& Buss, A.H. (1975). Public and private selfconsciousness:Assessment and theory. Journal of Consulting and Clinical Psychology, 43(4), 522-527.doi: $10.1037 / \mathrm{h} 0076760$.

Fogg, B.J. (2008). Mass interpersonal persuasion: An early view of a new phenomenon. In: Third International Conference on Persuasive Technology. Berline: Springer.

Kanter, M., Afifi, T., \& Robbins, S. (2012). The impact of parents "friending" their young children on Facebook on perceptions of parental privacy invasions and parent-child relationship quality. Journal of Communication, 62(5), 900-917. doi: 10.1111/j.1460 2466.2012.01669.x

Lapsley, D.K. (1985). Elkind on egocentrism. Developmental Review, 5(3), 227-236. doi: $\underline{10.1016 / 0273-2297(85) 90011-5}$

Lapsley, D.K., \& Murphy, M. (1985). Another look at the theoretical assumption of adolescent egocentrism. Developmental Review, 5(3), 201-217. doi: 10.1016/0273 2297(85)90009-7

Lapsley, D.K., \& Rice, K.G. (1988). The "new look" at the imaginary audience and personal fable: Toward a general model of adolescent ego development. In D. K. Lapsley \& F.C. Power (Eds.), Self, ego, and identity: Integrative approaches (pp.109-129). New York: Springer.

Lapsley, D.K., FitzGerald, D.P., Rice, K.G., \& Jackson, S. (1989). Separation individuation and the "new look" at the imaginary audience and personal fable: A test of an integrative model. Journal of Adolescent Research, 4(4), 483-505. doi: 10.1177/074355488944006

Lenhart, A. (2009a). Teens and social media: An overview. Washington, DC: Pew Internet \& American Life Project.

Lenhart, A. (2009b). Adults and social network websites. Washington, DC: Pew Internet \& American Life Project.

Lenhart, A., Purcell, K., Smith, A., \& Zickuhr, K. (2010). Social media and mobile Internet use among teens and young adults. Washington, DC: Pew Internet \& American Life Project.

McLaughlin, C., \& Vitak, J. (2012). Norm evolution and violation on Facebook. New Media \& Society, 14(2), 299-315. doi: 10.1177/1461444811412712

Moreno, M.A., Briner, L.R., Williams, A., Walker L, Christakis, D.A. (2009). Real use or "real cool": Adolescents speak out about displayed alcohol references on social networking websites. Journal of Adolescent Health, 45, 420-422. doi:10.1016/j.jadohealth.2009.04.015

Moreno, M. (2010). Social networking sites and adolescents. Pediatric Annals, 39(9), 565-568. 
Nickerson, A.B., \& Nagle, R.J. (2005). Parent and peer attachment in late childhood and early adolescence. The Journal of Early Adolescence, 25(2), 223-249.

doi: $101177 / 0272431604274174$

Piaget, J. (1952). The child's conception of number. New York: Humanities Press.

Remondet, J.H., Hansson, R.O., Rule, B., \& Winfrey, G. (1987). Rehearsal for widowhood. Journal of Social and Clinical Psychology, 5(3), 285-297.

Schwartz, P.D., Maynard, A.M., \& Uzelac, S.M. (2008). Adolescent egocentrism: A contemporary view. Adolescence, 43(171), 441-448.

Steele, J.R., \& Brown, J.D. (1995). Adolescent room culture: Studying media in the context of everyday life. Journal of Youth and Adolescence, 24, 551-577.

Subrahmanyam, K., Reich, S.M., Waechter, N., \& Espinoza, G. (2008). Online and offline social networks: Use of social networking sites by emerging adults. Journal of Applied Developmental Psychology, 29, 420-433. doi:10.1016/j.appdev.2008.07.003

Sullivan, H.S. (1953). The interpersonal theory of psychiatry. New York, NY: Norton.

Valkenburg, P.M., \& Peter, J. (2008). Adolescents' identity experiments on the Internet: Consequences for social competence and self-concept unity. Communication Research, 35(2), 208-231. doi: 10.1177/0093650207313164

Valkenburg, P.M., Peter, J., \& Schouten, A.P. (2006). Friend networking sites and their relationship to adolescents" well-being and social self-esteem. CyberPsychology \& Behavior, 9(5), 584-590. doi: 10.1089/cpb.2006.9.584

Vartanian, L.R. (1997). Separation-individuation, social support, and adolescent egocentrism: An exploratory study. Journal of Early Adolescence, 17, 245-270. doi:

$10.1177 / 0272431697017003001$

Vygotsky, L. (1978). Mind in Society: The development of higher psychological processes. Cambridge, MA: Harvard University Press.

Walther, J.B., Van Der Heide, B., Kim, S.-Y., Westerman, D., \& Tong, S.T. (2008). The role offriends' appearance and behavior on evaluations of individuals on Facebook: Are we known by the company we keep? Human Communication Research, 34, 28-49. doi: 10.1111/j.14682958.2007.00312.x

Wartella, E., Caplovitz, A.G., \& Lee, J.H. (2004). From baby Einstein to leapfrog, from doom to The Sims, from instant-messaging to Internet chat rooms: Public interest in the role of interactive media in children's lives. Social Policy Report, 18, 3-16.

(C) Copyright of Journal of Youth Development $~$ Bridging Research and Practice. Content may not be copied or emailed to multiple sites or posted to a listserv without copyright holder's express written permission. Contact Editor at: patricia.dawson@oregonstate.edu for details. However, users may print, download or email articles for individual use.

ISSN 2325-4009 (Print); ISSN 2325-4017 (Online) 